\title{
In-Hospital Postoperative Complications in Patients With Pituitary Adenoma Who Underwent Pituitary Surgery From January 2010 to December 2015: A Multicenter Study
}

\author{
Claire Carampatana-Jandug, ${ }^{\mathrm{a}, \mathrm{e}}$, Jonis Michael Esguerra ${ }^{\mathrm{b}}$, Gorgonia Panilagao $^{\mathrm{a}}$, \\ Athena Mejia $^{a}$, Jaime Rama ${ }^{b, c}$, Florenz Eubil Bilocura ${ }^{\mathrm{d}}$
}

\begin{abstract}
Background: Unwanted postoperative complications in pituitary surgeries pose significant morbidity and mortality. We examine the various in-hospital postoperative complications in two tertiary training hospitals.
\end{abstract}

Methods: This is a retrospective cohort study. Clinical, biochemical/ hormonal and neuroradiological evaluations were described. Postoperative complications were determined during the entire length of hospital stay.

Results: A total of 71 patients with pituitary adenoma who underwent pituitary surgery were studied. The mean age was 44 years old (range 18 - 77), female to male distribution was 1:1 (36:35), and mean body mass index (BMI) was $25 \mathrm{~kg} / \mathrm{m}^{2}$. The most common clinical presentation was visual disturbances $(80 \%)$, headache $(49 \%)$, and nausea and vomiting (21\%). Hypopituitarism was present in 32 patients $(45 \%)$. Seventy percent were macroadenomas. Non-functioning pituitary adenoma (NFPA) predominated (78\%), followed by prolactinoma $(17 \%)$, adrenocorticotropic hormone $(\mathrm{ACTH})$-secreting pituitary adenoma (Cushing's disease) (4\%) and growth hormone (GH)-secreting pituitary adenoma (acromegaly) (1\%). Giant pituitary adenoma was noted in 20\%. In-hospital postoperative complications occurred in 23 patients (32\%). The identified complications were diabetes insipidus $(22.5 \%)$, intracranial hemorrhage/hematoma $(8.5 \%)$, transient cerebrospinal fluid (CSF) leak (7\%), worsening of vision $(2.8 \%)$, headache $(2.8 \%)$, obstructive hydrocephalus $(2.8 \%)$, seizure $(2.8 \%)$, death $(2.8 \%)$, and hospital-acquired pneumonia (1.4\%). Among the possi-

Manuscript submitted June 22, 2017, accepted July 4, 2017

aSection of Endocrinology, Diabetes and Metabolism, Department of Internal Medicine, Chong Hua Hospital, Cebu City, Philippines

${ }^{b}$ Department of Neurosurgery, Vicente Sotto Medical Center, Cebu City, Philippines

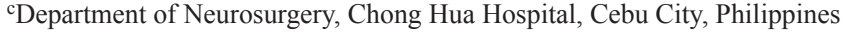
${ }^{\mathrm{d} D e p a r t m e n t}$ of Neurology, Department of Internal Medicine, Chong Hua Hospital, Cebu City, Philippines

${ }^{\text {e}}$ Corresponding Author: Claire Carampatana-Jandug, Section of Endocrinology, Diabetes and Metabolism, Department of Internal Medicine, Chong Hua Hospital, Fuente Osmena, Cebu City 6000, Philippines.

Email:kle2x@yahoo.com

doi: https://doi.org/10.14740/jem429w ble risk factors for the onset of complications, width of the tumor was the variable that reached statistical significance $(P=0.018)$.

Conclusion: Pituitary surgery is relatively safe. The most common immediate postoperative complications were diabetes insipidus, intracranial hemorrhage/hematoma and CSF leak. Larger tumor size was determined to be a risk factor for the onset of these complications.

Keywords: Pituitary adenoma; Complications; Postoperative

\section{Introduction}

Pituitary adenomas (PAs) are common central nervous system tumors. The incidence of PAs within the general population was known to reach by $20 \%[1-3]$.

PAs arise from the hormone-secreting epithelial cells in the adenohypophysis of the pituitary gland and are commonly benign [3]. They may be classified according to size (microadenomas are neoplasms $<1 \mathrm{~cm}$ confined within the sella turcica; macroadenomas are neoplasms $\geq 1 \mathrm{~cm}$ ) or may be classified as functional or non-functional $[4,5]$.

Patients with hypersecreting PAs, such as acromegaly or Cushing's disease, are subjected to undergo trans-sphenoidal surgical resection. In prolactinomas, however, surgical resection is considered when there is treatment failure with dopaminergic medications and/or experience severe side effects, tumoral mass effect and/or elect to undergo surgery. On the other hand, patients with non-functional PAs undergo surgery when clinically manifest mass effects are noted like visual disturbances, headaches, or hypopituitarism. The decision to undergo transcranial surgery is dictated mainly by the extension or invasiveness of the tumor like adenomas with prominent extrasellar extension and adenomas with extensive fibrosis; failed trans-sphenoidal surgery and inadequate decompression; and uncertain diagnosis [2].

According to a meta-analysis, the operative mortality of trans-sphenoidal surgery is less than $0.5 \%$ [6]. The potential complications of pituitary surgery are varied. For transsphenoidal approach, complications may be related to tumor characteristics, such as size and extrasellar extension, and others are related to surgical manipulation of the pituitary gland, 
hypothalamus and optic apparatus. For transcranial approach, complications generally relate to frontal lobe and optic nerve damage, and uncommonly, hypothalamic damage [2]. In the Philippines, Fonte et al identified the complications in the immediate postoperative period in patients who underwent pituitary surgery, namely, transient diabetes insipidus, cerebrospinal fluid (CSF) leak, hemorrhage, transient worsening of vision and death [7].

In our institution, postoperative complications after pituitary surgery have never been studied. Very few local studies were done, but mostly in Metro Manila area. With the notion that unwanted complications could pose significant morbidity and mortality to the affected patients, stripping them of their quality of life and may collaterally impale them, and their family as well, financially, identifying these complications and consequently, identifying the possible risk factors will better aid the clinician in the pre-operative treatment plan and prognosticating patients afflicted with the disease. Furthermore, identifying these risk factors will possibly pave the way for future risk-reduction strategies.

\section{Methods}

\section{Study patients}

After approval of the Institutional Review Board and Ethics Committee of both Chong Hua Hospital (a tertiary, private training hospital) and Vicente Sotto Memorial Medical Center (a tertiary, government training hospital), census of the patients aged 18 years old and above admitted to the general surgical patient care units and intensive care units from January 2010 to December 2015, who were diagnosed with PA and subsequently underwent pituitary surgery were gathered per institution. The list of patients was submitted to the Medical Records Section for retrieval. Chart review was done at the Medical Records Section at a specified schedule and was documented. The diagnosis was based on clinical presentation, hormonal evaluation, documented pituitary tumor by cranial computed tomography (CT) scan and/or magnetic resonance imaging (MRI) and histopathologic examination when available.

\section{Clinical, hormonal and neuroradiological evaluation}

The clinical presentation of the affected patients was noted based on the recorded complaints in the medical history. Visual disturbances include blurring of vision, blindness, double vision, and visual distortion, may it be transient, intermittent or persistent. Signs and symptoms of hypogonadism include erectile dysfunction, decrease in libido, amenorrhea, and infertility.

The hormonal evaluation was based on the usual hormonal evaluation tests of the type of PA, which include serum levels of growth hormone $(\mathrm{GH})$, prolactin (PRL), follicle-stimulating hormone $(\mathrm{FSH})$, luteinizing hormone $(\mathrm{LH})$, estradiol, testosterone, adrenocorticotrophic hormone (ACTH), 8 am cortisol, thyroid-stimulating hormone (TSH), free thyroxine (fT4) and free triiodothyronine (fT3). The occurrence of hypopituitarism was noted when at least one biochemical deficiency was determined. Central hypothyroidism was noted when the serum levels of fT4 and/or free thyronine were suppressed with concurrent low or normal TSH levels.

For the neuroradiological evaluation, the tumor was categorized as microadenoma or macroadenoma based on its size $[4,5]$. There are classification systems that characterize invasiveness of PAs. The Hardy classification system defines the extension of the sellar mass from the confines of the sella to suprasellar, parasellar and extrasellar areas. The Knosp classification system, on the other hand, is used to quantify invasion of the cavernous sinus $[1,8]$.

In this study, the immediate postoperative complications were determined based on the study by Fonte et al [7]. Subsequently, the univariate and multivariate analyses with the possible risk factors were also ascertained.

\section{Data analysis}

To describe the patients' demographics, clinical presentation, hormonal evaluation results, neuroradiological evaluation, and surgical management given and their indications, categorical variables were expressed in frequency and percentages while continuous or quantitative profiles were indicated by mean and standard deviation (SD). Furthermore, rates of complications were also computed.

Test of associations among categorical variables was performed using Chi-square test with $2 \times 2$ Fisher exact test adjustment. Those independent variables, which were significantly associated with complications, were subjected to multivariate risk factor analysis using logistic regression in order to identify risk factors as potential predictors of complications. Odds ratio with $95 \%$ CI was also be estimated among risk factors. Any associated P-values lesser than 0.05 alpha were considered significant. IBM SPSS ver. 21 was used as statistical software.

\section{Results}

A total of 71 patients with PA who underwent pituitary surgery were included in the study. The mean age was 44 years old; the youngest was 18 years old and the oldest was 77 years old. There was approximately 1:1 female to male distribution (36:35). The mean body mass index (BMI) was $25 \mathrm{~kg} / \mathrm{m}^{2}$. Around 29 patients $(41 \%)$ had co-morbidities, mainly hypertension $(n=20)$ and type 2 diabetes mellitus $(n=17)$. Majority of the patients $(n=66)$ had no previous pituitary surgery. The most common clinical presentation was visual disturbances (n $=57)$, headache $(\mathrm{n}=35)$, and nausea and vomiting $(\mathrm{n}=15)$.

Of all the confirmed cases, clinically non-functioning pituitary adenoma (NFPA) predominated $(n=55)$. Among the hypersecreting PA $(n=16)$, majority were prolactin-secreting PA (prolactinoma) $(n=12)$, followed by adrenocorticotropic hormone (ACTH)-secreting PA (Cushing's disease) $(\mathrm{n}=3)$ and growth hormone $(\mathrm{GH})$-secreting PA (acromegaly) $(\mathrm{n}=1)$. 
Table 1. Hormonal and Neuroradiological Evaluation and Surgical Management of Patients With Pituitary Adenoma

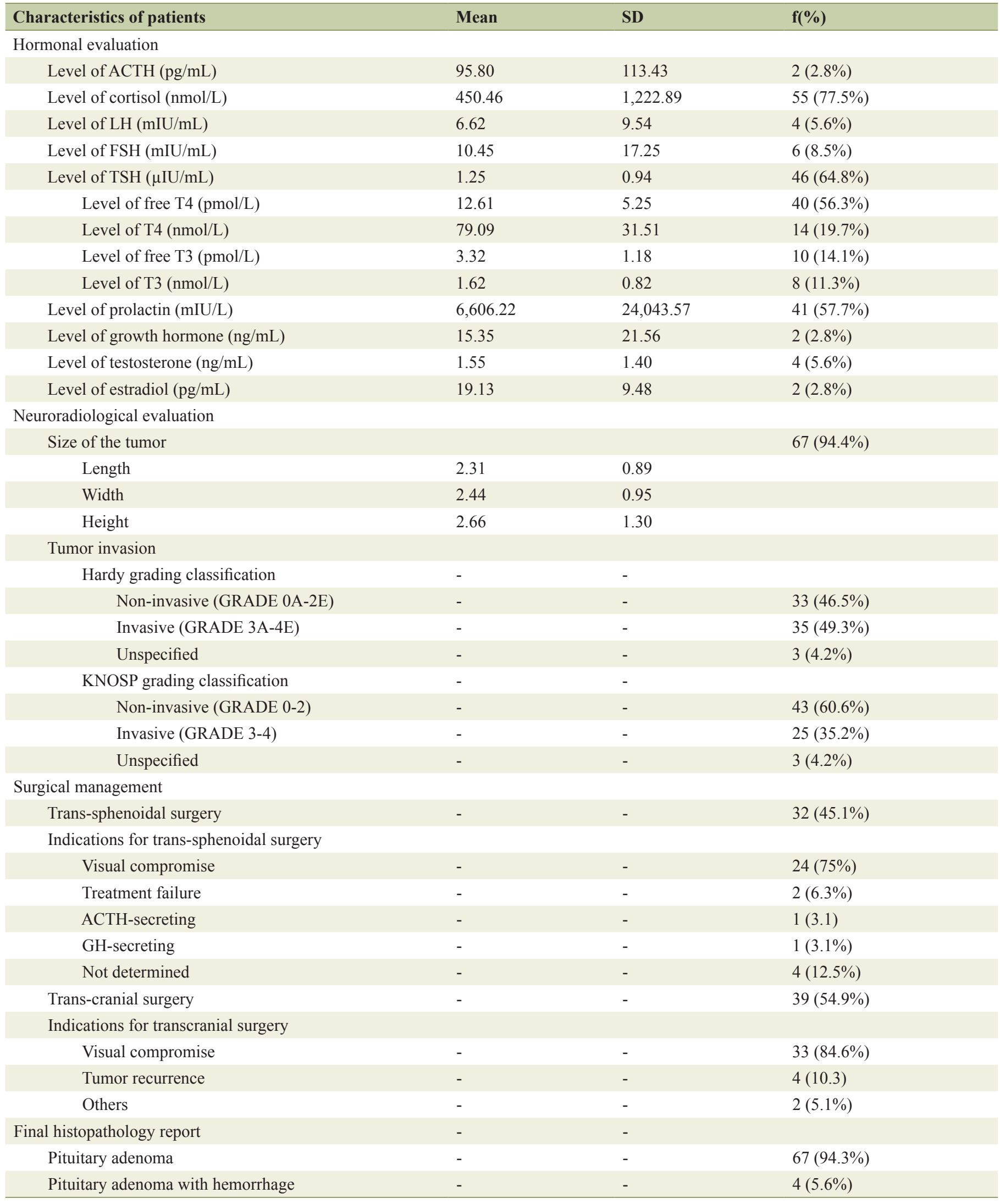


Table 2. Immediate Postoperative Complications

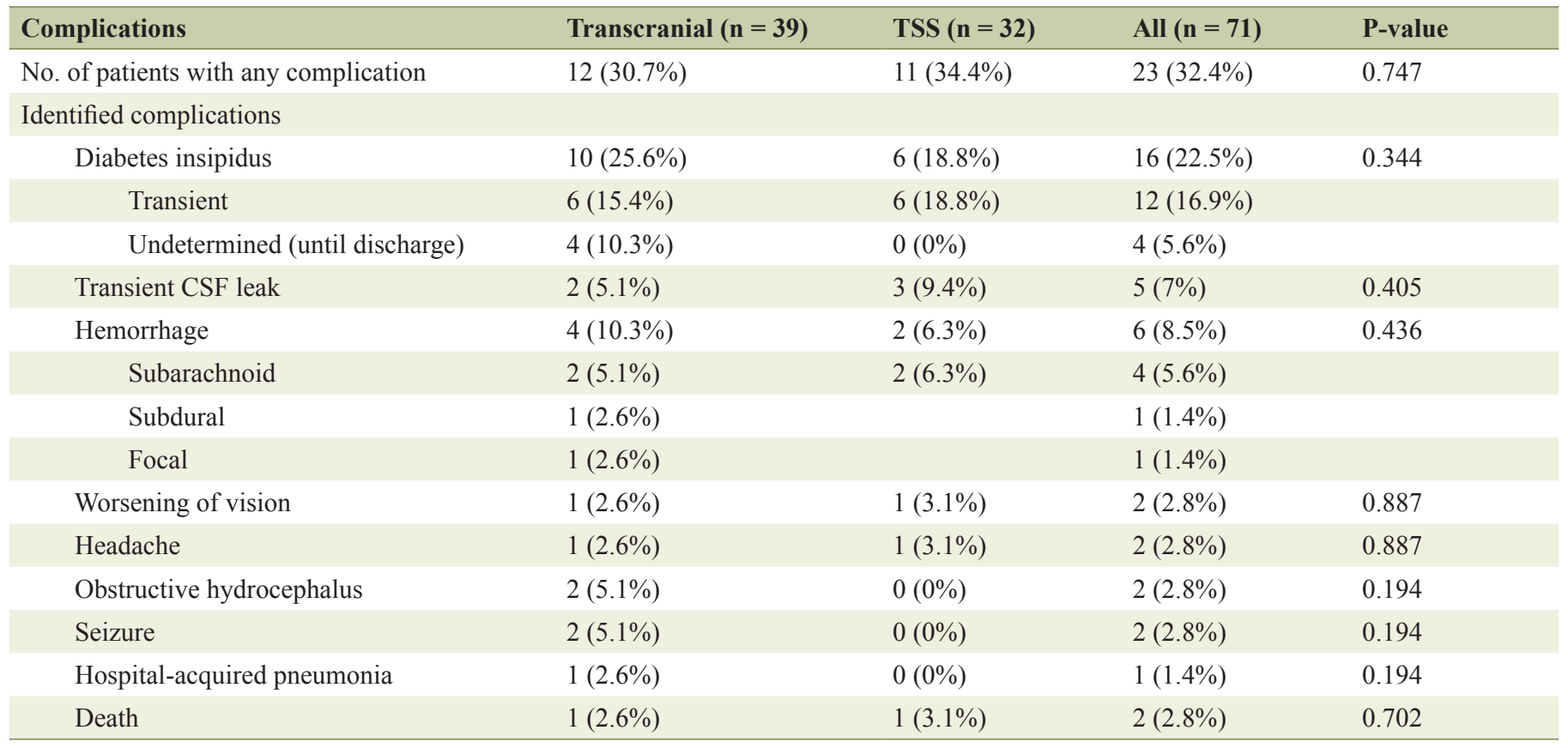

Giant PA with at least $4 \mathrm{~cm}$ at its greatest diameter was also noted at $20 \%(n=14)$. Among the giant PA, NFPA was commonly noted $(n=8)$, followed by giant prolactinoma $(n=6)$. Hypopituitarism was present in $45 \%(n=32)$ of patients; eight patients had isolated central hypothyroidism and five patients had isolated hypocortisolism. The average length of hospital stay was 13 days.

Among patients with NFPA, the mean age was 40 years old (SD 15). It was predominantly seen among males $(63 \%)$. The mean BMI was $24 \mathrm{~kg} / \mathrm{m}^{2}$. The clinical manifestations commonly seen were headache $(82 \%)$, visual disturbance (49\%), and nausea and vomiting (13\%). Hypopituitarism occurred in $47 \%$ of patients.

The mean age among patients with prolactinoma was 41 years old (SD 13). There was no sex predilection (female/male is $1: 1)$. The most common clinical manifestations were visual disturbance $(83 \%)$, headache $(67 \%)$, and signs and symptoms of hypogonadism (33\%). The signs and symptoms of hypogonadism were more commonly seen in patients with prolactinoma and this association was statistically significant (Pvalue 0.02 ). Half of the affected patients had hypopituitarism.

There were only three patients with Cushing's disease. Baseline characteristics include mean age of 47 years old (SD 13), male predominance (67\%), average BMI of $25 \mathrm{~kg} / \mathrm{m}^{2}$ (SD $5)$, co-morbidities (67\%), and no previous pituitary surgery $(100 \%)$. The clinical manifestations were mainly Cushingoid features (moon facie and plethora) (67\%) (P-value $\leq 0.001)$ and visual disturbance $(67 \%)$.

There was only one patient with a $\mathrm{GH}$-secreting tumor in a 58 -year-old female with a BMI of $24 \mathrm{~kg} / \mathrm{m}^{2}$, with co-morbidities (hypertension and type 2 diabetes mellitus), and no previous pituitary surgery. Clinical features were coarse facial features like frontal bossing and macroglossia ( $\mathrm{P}$-value $\leq 0.001)$.
TSH-secreting PA was not observed in this study.

In the hormonal evaluation of the PA (Table 1), the mean level of cortisol was $450 \mathrm{nmol} / \mathrm{L}$. The mean TSH was 1.25 $\mu \mathrm{IU} / \mathrm{L}$, fT4 was $12.61 \mathrm{pmol} / \mathrm{L}$, and free triiodothyronine (fT3) was $3.32 \mathrm{pmol} / \mathrm{L}$. The average prolactin level was 6,606 $\mathrm{mIU} / \mathrm{L}$.

The mean tumor size was $2.3 \mathrm{~cm}(\mathrm{SD} 0.89) \times 2.4 \mathrm{~cm}(\mathrm{SD}$ $0.95) \times 2.6 \mathrm{~cm}(\mathrm{SD} 1.30)$ (length $\times$ width $\times$ height $).$ In the Hardy grading system, almost half of patients had invasive tumors $(n=35)$. In the Knosp grading system, 25 of patients had cavernous sinus invasion.

There were slightly more patients with PA who underwent transcranial pituitary surgery $(55 \%)$. The most common indications for surgery were visual compromise (85\%) and tumor recurrence $(10 \%)$. Among the patients who underwent transsphenoidal surgery $(45 \%)$, the most common indications were visual compromise $(75 \%)$, treatment failure $(6 \%)$, and hypersecreting tumors (ACTH-secreting and $\mathrm{GH}$-secreting tumors) at $6.2 \%$.

On the final histopathologic report, there were 94\% confirmed cases of PA. There were four $(6 \%)$ patients with PA with hemorrhage.

In this study, any in-hospital postoperative complications (Table 2$)$ were noted in $32 \%(n=23)$ of the study population. The identified complications were diabetes insipidus $(n=16)$, intracranial hemorrhage/hematoma $(n=6)$, transient CSF leak $(n=5)$, worsening of vision $(n=2)$, headache $(n=2)$, obstructive hydrocephalus $(n=2)$, seizure $(n=2)$, death $(n=2)$, and hospital-acquired pneumonia $(\mathrm{n}=1)$. There was no significant difference between doing trans-sphenoidal versus transcranial pituitary surgery. It was noteworthy, however, that for patients who underwent transcranial surgery, diabetes insipidus was more prolonged (noted until discharge and possibly beyond) 
Table 3. Univariate Test Between Patient's Clinical Profile and the Presence of Complications

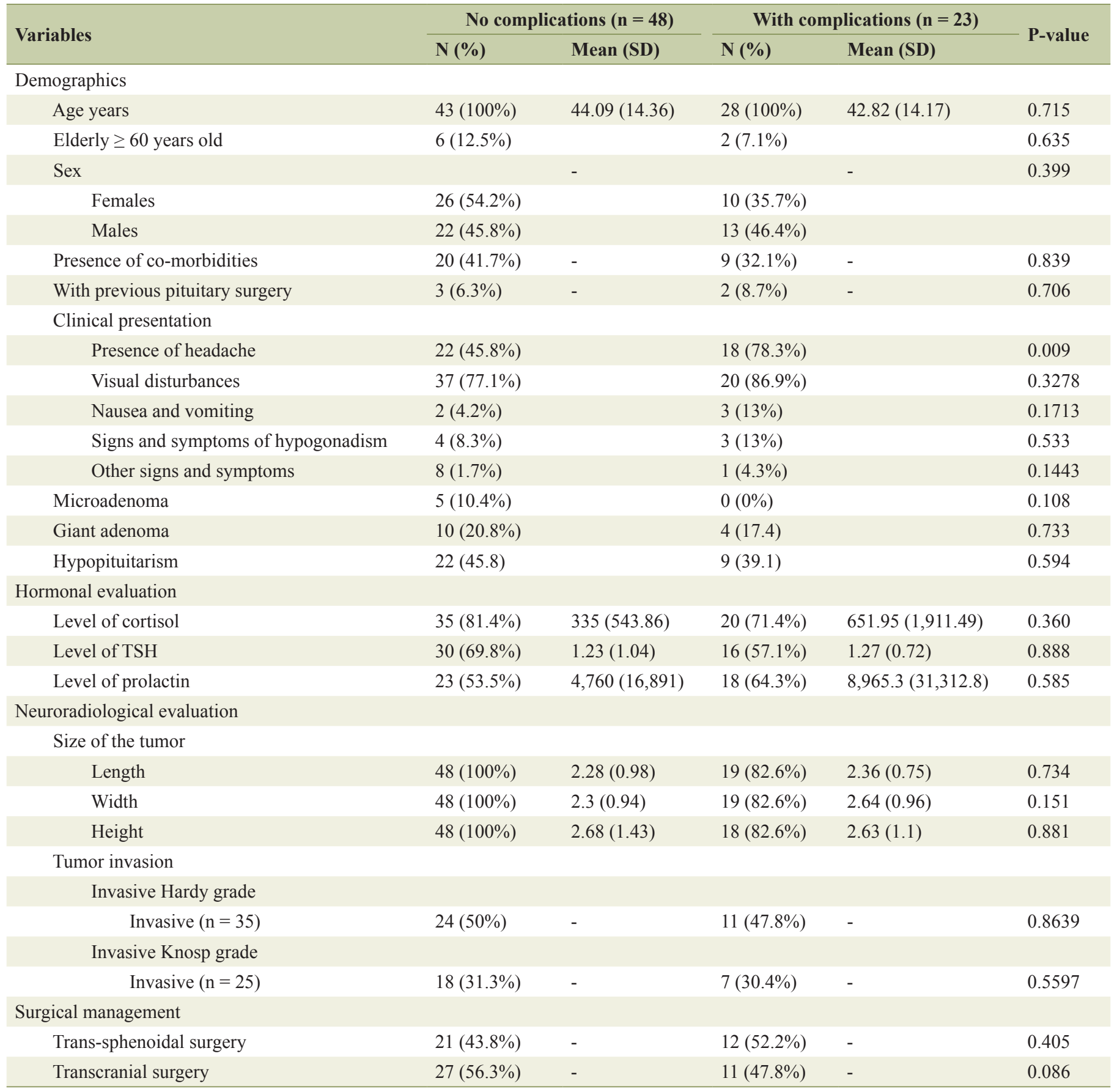

$(10.3 \%$ vs. $0 \%)$, greater incidence of intracranial hemorrhage ( $10.3 \%$ vs. $6.4 \%)$, obstructive hydrocephalus $(5.1 \%$ vs. $0 \%)$, seizure $(5.1 \%$ vs. $0 \%)$, and onset of hospital-acquired pneumonia $(2.6 \%$ vs. $0 \%)$. These observations were statistically not significant.

There were two patients who died. One patient was a 27-year-old female with no co-morbidities, diagnosed with macroprolactinoma, presenting with visual disturbance and amenorrhea. Patient underwent transcranial pituitary surgery.
On the second postoperative day, she developed subarachnoid hemorrhage with obstructive hydrocephalus. Patient subsequently expired due to overwhelming sepsis secondary to hospital-acquired pneumonia and disseminated intravascular coagulopathy. The other patient was a 52-year-old male, diabetic, diagnosed with non-functioning pituitary macroadenoma with hypopituitarism. Patient underwent trans-sphenoidal pituitary surgery and postoperatively, developed subarachnoid hemorrhage necessitating craniotomy for evacuation of hematoma. 
Table 4. Multivariate Analysis on Postoperative Complications

\begin{tabular}{|c|c|c|c|c|c|c|}
\hline \multirow{2}{*}{ Variables in the equation } & \multirow{2}{*}{ B } & \multirow{2}{*}{ SE } & \multirow{2}{*}{ P-value } & \multirow{2}{*}{ OR } & \multicolumn{2}{|c|}{$95 \% \mathrm{CI}$} \\
\hline & & & & & Lower & Upper \\
\hline Age & -0.002 & 0.022 & 0.929 & 0.998 & 0.956 & 1.042 \\
\hline Headache & 0.629 & 0.587 & 0.284 & 1.875 & 0.594 & 5.924 \\
\hline Visual disturbance & -0.906 & 0.938 & 0.334 & 0.404 & 0.064 & 2.539 \\
\hline Size of tumor width & 1.601 & 0.675 & 0.018 & 4.959 & 1.32 & 18.624 \\
\hline Size of tumor height & -0.9 & 0.492 & 0.067 & 0.407 & 0.155 & 1.066 \\
\hline Trans-sphenoidal surgery & 0.187 & 0.658 & 0.776 & 1.206 & 0.332 & 4.381 \\
\hline Constant & -0.978 & 1.45 & 0.500 & 0.376 & & \\
\hline
\end{tabular}

Patient also succumbed to overwhelming sepsis. In this study, the mortality rate was $2.8 \%$.

A univariate test was done to find any association of patients' characteristics and other variables with the occurrence of immediate postoperative complications (Table 3). Age was not a statistically significant factor in the onset of complications. Among those with complications, 39\% had hypopituitarism, 32\% had co-morbidities, $17 \%$ had giant adenoma, $9 \%$ had previous pituitary surgery, and $7.1 \%$ of the affected patients belong to the elderly population. Among those with no complications, majority were females (54\% vs. $46 \%$ ), had lesser incidence of headache (46\% vs. $78 \%$ ) and visual disturbance $(77 \%$ vs. $87 \%)$ as the initial clinical presentation, and were harboring microadenoma (100\% vs. 0\%). These associations did not reach statistical significance except for the presence of headache as a clinical presentation.

A multivariate analysis was done on complications to determine any risk factor. The variables included in Table 4 were the only variables that were eligible for analysis. Tumor size was the only risk factor determined, specifically the width of the tumor.

\section{Discussion}

In this study, majority of the patients with PAs were harboring macroadenomas and NFPA, with a mean age of 44 years old, and almost equal distribution among sex. Similar findings were reported by Fonte and colleagues [7] in a local study. Internationally, a Surveillance, Epidemiology, and End Results (SEER) Program in the United States reportedly claimed that the pituitary tumor median size was $1.5-2.3 \mathrm{~cm}$ [9]. The clinical manifestations can range from mass effect on structures adjacent to the pituitary that commonly lead to hypopituitarism to signs and symptoms of hypersecretion of specific hormones [10]. Similarly, in this study, clinical presentation was most commonly due to tumoral mass effects, which include visual disturbance, headache, and hypopituitarism.

PAs are slow-growing. The direction of growth is commonly towards the suprasellar space compressing the optic chiasm. Some PAs can invade downwards into the sphenoid sinus or laterally into the cavernous sinus [11]. In this study, most of the PA had suprasellar and parasellar extension. These observations parallel that of the study by Fonte and colleagues [7].

\section{NFPAs (hormonally inactive)}

NFPA is the most commonly reported indication for pituitary surgery (about $50 \%$ of operated PAs) [12]. In this study, majority of patients who underwent pituitary surgery were harboring NFPAs. Clinical manifestations of these patients were similar to those found in literature, typically presenting with visual disturbance and/or hypopituitarism related to mass effect of the tumor. Compression of the stalk may cause mild to moderate hyperprolactinemia in many NFPAs. Clinically, NFPAs can usually be distinguished from prolactinomas. Prolactinomas typically secrete prolactin that exceed $250 \mu \mathrm{g} / \mathrm{L}$ and may exceed 1,000 $\mu \mathrm{g} / \mathrm{L}$. Prolactin levels from NFPAs virtually never exceed $94 \mu \mathrm{g} / \mathrm{L}$ [13]. In this study, patients presented with normal to mild hyperprolactinemia.

\section{Functioning PAs (hormonally active)}

Prolactinomas are the most common hormone-secreting tumors of the pituitary gland, representing up to $40 \%$ of all pituitary tumors [14]. They present as microadenomas in $90 \%$ of cases and appear most frequently in females aged between 20 and 50 years; the sex ratio is (10 - 20):1 [1] and for macroadenomas the gender ratio is roughly equivalent $[1,15]$. In this study, majority of functional adenomas were macroprolactino$\mathrm{ma}$, and indeed, the sex distribution was equal. The mean age was 41 years old (age range 22 - 58). Premenopausal women typically present with amenorrhea, infertility, and galactorrhea, which were also seen in our study.

Cushing's disease was present in three patients, in which two of them had macroadenoma. In the literature, patients with Cushing's disease commonly have microadenoma [16]. How- 
ever, there may be $4-10 \%$ of patients with larger tumors (more than $10 \mathrm{~mm}$ in diameter) [17]. In a study done by Hwang and colleagues [18], wherein comparisons between macroadenomas and microadenomas in Cushing's disease were made, macroadenomas were not different from the biochemical tests and clinical outcomes of the disease that was caused by microadenoma.

Acromegaly is due to an excessive production of growth hormone. It is marked by gradual physical dysmorphic changes $[19,20]$. There is a higher preponderance of macroadenomas $(>65 \%)$ in acromegaly; hence, local signs are especially important presenting features [1]. In this study, however, with only one case of acromegaly, the mass noted was a microadenoma in a 58-year-old, overweight female with associated hypertension and diabetes. Frontal bossing and macroglossia were the only features mentioned. Microadenoma in acromegaly is uncommon. In a study done by Park and colleagues [21], only $15 \%$ of acromegalic patients presented with microadenoma. Patients with microadenoma were found to be older and had lower BMI and a lower prevalence of hyperprolactinemia and hypogonadism.

\section{Surgical management}

In this study, more than half of cases were surgically managed by the transcranial approach with visual compromise and treatment failure as the most common surgical indications. It could also be surmised that invasive tumors commonly seen in this study and in fact, $20 \%$ were giant adenoma, may have contributed to the decision of the surgical approach. Current surgical approach to pituitary surgery is through the trans-sphenoidal route. Extensive invasiveness of the tumor has conventionally been observed as a contraindication for the trans-sphenoidal approach. However, there are also comprehensive surgical modifications that permit access and provide effective initial management of giant PAs with favorable results [22]. There are certain features that favor the transcranial open craniotomy over the trans-sphenoidal route, specifically, significant supraor retrosellar or lateral extensions of the tumor, brain invasion with edema, firm tumor consistency, involvement or vasospasm of the arteries of the circle of Willis, and encasement of the optic apparatus or invasion of the optic foramina [23]. In this study, almost half of patients had extensive tumors and one-third had cavernous sinus invasion. The key to choosing between the trans-sphenoidal and transcranial approach is individualization and sufficient preoperative evaluation, taking into account the characteristics of the tumor and the patient's clinical status, and the capability and expertise of the surgical team [24].

\section{Postoperative complications}

In this study, postoperative complications were noted in a remarkable number $(32 \%)$ of patients. The most common complications were diabetes insipidus, hemorrhage, and transient CSF leak. Other complications were worsening of vision, headache, obstructive hydrocephalus, seizure, hospital-ac- quired pneumonia, and death. Similarly, in the literature, complications related to the trans-sphenoidal approach are mainly CSF leak followed by diabetes insipidus, postoperative nausea and vomiting, and hematoma at operation site $[25,26]$. On the other hand, potential risks for the transcranial approach are frontal lobe damage manifested postoperatively as changes in memory, judgment, concentration, personality and anosmia [2]. These clinical manifestations were not reported in this study. Other significant complications are injuries to the optic nerve, internal carotid artery and hypothalamus [27]. Correspondingly, in the local study done by Fonte et al [7], similar incidence rate of immediate postoperative complications was noted. Transient diabetes insipidus was the most common complication, followed by CSF leak, hemorrhage, transient worsening of vision, and death.

\section{Diabetes insipidus}

Diabetes insipidus is one of the common complications in the immediate postoperative period following pituitary surgery. It can occur in $16-38 \%$ of patients $[28,29]$. It usually occurs during the first postoperative day and completely resolves within 10 days [28]. In few patients, it may persist and require antidiuretic hormone analogs. This was comparable with our study, in which $22.5 \%$ of patients had diabetes insipidus and majority of cases were transient in nature.

\section{Hemorrhage}

Vascular complications are among the most feared complications following pituitary surgeries, occurring in about $1 \%$ [6]. In this study, a higher incidence of $9 \%$ resulted to intracranial hemorrhage/hematoma. It was noteworthy to mention that two of the patients who underwent trans-sphenoidal surgery developed subarachnoid hemorrhage postoperatively, thereby necessitating craniotomy for evacuation of hematoma.

\section{CSF leak}

Disruption of the arachnoid membrane during trans-sphenoidal pituitary surgery is usually the cause of CSF rhinorrhea. This occurs in $3-13 \%$ of cases $[30,31]$. Similarly, in this study, CSF leak occurred in five $(7 \%)$ patients. These cases were transient and resolved spontaneously.

\section{Risk factors}

The suggested risk factors that predispose to postoperative complications after pituitary surgery are tumor volume and histopathology, advanced age, body mass index, repeat operation, and previous radiotherapy $[10,32,33]$. In this study, the only identified risk factor for the onset of any postoperative complication was larger tumor size, specifically the width of the tumor. 


\section{Limitations}

The neurosurgeons involved in the actual surgical procedure in this study may have variable expertise. This may explain the differences in postoperative complications noted in most literature. With regard to the NFPAs, the specific type of adenohypophyseal cell was not ascertained and complete biochemical tests were lacking. Moreover, multivariate analysis could not be done on some parameters due to incomplete data and small sample size.

\section{Conclusions}

Pituitary surgery is relatively a safe procedure with mortality rate of 3\% in this study. Transcranial approach of pituitary surgery was the most preferred mode of surgery due to large and invasive tumors involved. The most common in-hospital postoperative complications were diabetes insipidus, intracranial hemorrhage/hematoma and CSF leak. Larger tumor size was determined to be a risk factor for the onset of these complications.

\section{Acknowledgments}

The authors would like to express gratitude to the Section of Endocrinology, Diabetes and Metabolism of Chong Hua Hospital and the Department of Neurosurgery in Vicente Sotto Memorial Medical Center. The Medical Records Sections of both institutions have also been of great help.

\section{Conflicts of Interest}

No potential conflicts of interest relevant to this article were reported.

\section{References}

1. Melmed S, Polonsky KS, Larsen PR, Kronenberg HM. Williams Textbook of Endocrinology. 13th edition. Philadelphia, United States: Elsevier; 2016:251-287.

2. Theodros D, Patel M, Ruzevick J, Lim M, Bettegowda C. Pituitary adenomas: historical perspective, surgical management and future directions. CNS Oncol. 2015;4(6):411-429.

3. Asa SL, Ezzat S. The cytogenesis and pathogenesis of pituitary adenomas. Endocr Rev. 1998;19(6):798-827.

4. Melmed S. Pathogenesis of pituitary tumors. Nat Rev Endocrinol. 2011;7(5):257-266.

5. Ezzat S, Asa SL, Couldwell WT, Barr CE, Dodge WE, Vance ML, McCutcheon IE. The prevalence of pituitary adenomas: a systematic review. Cancer. 2004;101(3):613619.

6. Ammirati M, Wei L, Ciric I. Short-term outcome of endoscopic versus microscopic pituitary adenoma surgery: a systematic review and meta-analysis. J Neurol Neurosurg
Psychiatry. 2013;84(8):843-849.

7. Fonte JS, Cunanan EC, Matawaran BJ, Mercado-Asis LB. Treatment outcomes of pituitary tumors at the university of Santo Tomas hospital: 2004-2008. Phil J Internal Medicine. 2009;47:121-128.

8. Knosp E, Steiner E, Kitz K, Matula C. Pituitary adenomas with invasion of the cavernous sinus space: a magnetic resonance imaging classification compared with surgical findings. Neurosurgery. 1993;33(4):610-617; discussion 617-618.

9. McDowell BD, Wallace RB, Carnahan RM, Chrischilles EA, Lynch CF, Schlechte JA. Demographic differences in incidence for pituitary adenoma. Pituitary. 2011;14(1):2330.

10. Freda PU, Bruce JN. Surgery: Risks of pituitary surgery in the elderly. Nat Rev Endocrinol. 2010;6(11):606-608.

11. Karppinen Atte. Outcome after transsphenoidal surgery for pituitary adenoma. The 2000-2010 Helsinki University Hospital Cohort. 2015.

12. Saeger W, Ludecke DK, Buchfelder M, Fahlbusch R, Quabbe HJ, Petersenn S. Pathohistological classification of pituitary tumors: 10 years of experience with the German Pituitary Tumor Registry. Eur J Endocrinol. 2007;156(2):203-216.

13. Chahal J, Schlechte J. Hyperprolactinemia. Pituitary. 2008;11(2):141-146.

14. Samarasinghe S, Emanuele MA, Mazhari A. Handbook of Clinical Neurology. Elsevier; 2014:685-701.

15. Colao A. Pituitary tumours: the prolactinoma. Best Pract Res Clin Endocrinol Metab. 2009;23(5):575-596.

16. Castinetti F, Morange I, Conte-Devolx B, Brue T. Cushing's disease. Orphanet J Rare Dis. 2012;7:41.

17. Woo YS, Isidori AM, Wat WZ, Kaltsas GA, Afshar F, Sabin I, Jenkins PJ, et al. Clinical and biochemical characteristics of adrenocorticotropin-secreting macroadenomas. J Clin Endocrinol Metab. 2005;90(8):4963-4969.

18. Hwang YC, Chung JH, Min YK, Lee MS, Lee MK, Kim KW. Comparisons between macroadenomas and microadenomas in Cushing's disease: characteristics of hormone secretion and clinical outcomes. J Korean Med Sci. 2009;24(1):46-51.

19. Chanson P, Salenave S, Kamenicky P, Cazabat L, Young J. Pituitary tumours: acromegaly. Best Pract Res Clin Endocrinol Metab. 2009;23(5):555-574.

20. Kauppinen-Makelin R, Sane T, Reunanen A, Valimaki MJ, Niskanen L, Markkanen H, Loyttyniemi E, et al. A nationwide survey of mortality in acromegaly. J Clin Endocrinol Metab. 2005;90(7):4081-4086.

21. Park JY, Kim JH, Kim SW, Chung JH, Min YK, Lee MS, Lee MK, et al. Using growth hormone levels to detect macroadenoma in patients with acromegaly. Endocrinol Metab (Seoul). 2014;29(4):450-456.

22. Koutourousiou M, Gardner PA, Fernandez-Miranda JC, Paluzzi A, Wang EW, Snyderman CH. Endoscopic endonasal surgery for giant pituitary adenomas: advantages and limitations. J Neurosurg. 2013;118(3):621-631.

23. Zada G, Du R, Laws ER, Jr. Defining the "edge of the envelope": patient selection in treating complex sellar-based neoplasms via transsphenoidal versus open craniotomy. J 
Neurosurg. 2011;114(2):286-300.

24. Nishioka H, Hara T, Usui M, Fukuhara N, Yamada S. Simultaneous combined supra-infrasellar approach for giant/large multilobulated pituitary adenomas. World Neurosurg. 2012;77(3-4):533-539.

25. Chowdhury T, Prabhakar H, Bithal PK, Schaller B, Dash $\mathrm{HH}$. Immediate postoperative complications in transsphenoidal pituitary surgery: A prospective study. Saudi J Anaesth. 2014;8(3):335-341.

26. Thomas JG, Gadgil N, Samson SL, Takashima M, Yoshor D. Prospective trial of a short hospital stay protocol after endoscopic endonasal pituitary adenoma surgery. World Neurosurg. 2014;81(3-4):576-583.

27. Recinos PF, Goodwin CR, Brem H, Quinones-Hinojosa A. Transcranial surgery for pituitary macroadenomas. In: Qui-ones-Hinojosa A, editor. Schmidek and Sweet Operative Neurosurgical Techniques. Elsevier Saunders; 2012:280-291.

28. Kristof RA, Rother M, Neuloh G, Klingmuller D. Incidence, clinical manifestations, and course of water and electrolyte metabolism disturbances following transsphenoidal pituitary adenoma surgery: a prospective observational study. J Neurosurg. 2009;111(3):555-562.

29. Adams JR, Blevins LS, Jr., Allen GS, Verity DK, Devin JK. Disorders of water metabolism following transsphenoidal pituitary surgery: a single institution's experience. Pituitary. 2006;9(2):93-99.

30. Elgamal E. CSF rhinorrhoea after transsphenoidal surgery. The Internet Journal of Neurosurgery. 2007;5(1).

31. Sudhakar N, Ray A, Vafidis JA. Complications after trans-sphenoidal surgery: our experience and a review of the literature. Br J Neurosurg. 2004;18(5):507-512.

32. Schreckinger M, Walker B, Knepper J, Hornyak M, Hong D, Kim JM, Folbe A, et al. Post-operative diabetes insipidus after endoscopic transsphenoidal surgery. Pituitary. 2013;16(4):445-451.

33. Nishioka H, Haraoka J, Ikeda Y. Risk factors of cerebrospinal fluid rhinorrhea following transsphenoidal surgery. Acta Neurochir (Wien). 2005;147(11):1163-1166; discussion 1166 . 